\title{
OS PROJETOS DE LETRAMENTO COMO INSTRUMENTOS DE RESSIGNIFICAÇÃO DO TEMPO, DO ESPAÇO E DOS MATERIAIS ESCOLARES
}

\section{LITERACY PROJECTS AS INSTRUMENTS OF RESSIGNIFICATION OF TIME, SPACE AND SCHOOL SUPPLIES}

\author{
Arisberto Gomes de Souza \\ Maria do Socorro Oliveira ${ }^{2}$ \\ Universidade Federal do Rio Grande do Norte
}

\begin{abstract}
RESUMO
Um dos pontos-chave dos projetos de letramento é o seu funcionamento, alinhado à dinâmica das práticas sociais que ocorrem em diversos contextos. Com base nisso, objetivamos empreender uma discussão voltada a entender como o processo de escrita cotidiana de alunos do ensino médio externo à escola pode inspirar o desenvolvimento de ações de ensinoaprendizagem ancoradas em projetos de letramento, especificamente no que tange à extrapolação dos horários, lugares e recursos específicos da sala de aula e da escola. Assim, na esteira de Barton e Hamilton (2000), Bazerman (2011), Heath (1982), Kleiman (1995, 2000, 2007), Oliveira (2008, 2010a, 2010b), Oliveira; Tinoco e Santos (2014) e Santos (2012), explicitamos os conceitos de letramento, gêneros, projetos de letramento, entre outros. A geração dos dados ocorreu por meio de uma entrevista endereçada a alunos do ensino médio, que falaram sobre suas práticas de escrita, suas formas de produção, a regularidade de usos e os recursos referentes a essas práticas. Como resultado, nossas reflexões contribuíram para o entendimento de que as práticas de escrita dos alunos que ocorrem fora do espaço escolar podem representar importantes fontes de inspiração para o delineamento e a execução de projetos de letramento.
\end{abstract}

PALAVRAS-CHAVE: Projetos de letramento; Escrita; Ensino-aprendizagem.

\begin{abstract}
One of the key points of the literacy projects is your operation, aligned to the dynamics of social practices that occur in various contexts. On the basis of this, we aim to undertake a discussion aimed to understand how the process of everyday writing of secondary students in Brazil external to school can inspire the development of teaching and learning anchored in literacy projects, specifically regarding the extrapolation of timetables, places and specific resources of the classroom and the school. In this way, in the light of Barton e Hamilton (2000), Bazerman (2011), Heath (1982), Kleiman (1995, 2000, 2007), Oliveira (2008, 2010a, 2010b), Oliveira; Tinoco e Santos (2014) and Santos (2012), we explain concepts such as literacy, genres, literacy projects and others. The data for this research was generated by interviews with secondary students in Brazil who spoke about their writing practices, ways of text production and the regularity of uses and resources regarding those practices. As a result, our discussion contributed to the understanding that those students' writing practices that take place out of school can represent important sources of inspiration to the design and execution of literacy projects.
\end{abstract}

KEYWORDS: Literacy Projects; Writing; Teaching-learning.

\footnotetext{
${ }^{1}$ Mestre em Letras pelo Programa de Pós-Graduação em Letras (UERN) e Doutorando em Estudos da Linguagem pelo Programa de Pós-Graduação em Estudos da Linguagem (UFRN). E-mail: aarisba@hotmail.com.

${ }^{2}$ Doutora em Linguística (UNICAMP). Professora titular do Departamento de Letras e do Programa de PósGraduação em Estudos da Linguagem (UFRN). E-mail: msroliveira.ufrn@gmail.com.
} 


\section{INTRODUÇÃO}

O mote da nossa discussão é a necessidade de argumentar acerca de uma importante característica dos projetos de letramento (doravante PL): a sua preocupação em proporcionar à escola vivências de ensino-aprendizagem ancoradas em práticas sociais cotidianas. Pensando nisso, objetivamos empreender uma discussão voltada a entender como a dinâmica de escrita cotidiana de alunos do ensino médio externa à escola pode inspirar o desenvolvimento de ações de ensino-aprendizagem ancoradas em projetos de letramento, especificamente no que tange à extrapolação dos horários, lugares e recursos específicos da sala de aula e da escola.

A nossa discussão encontra embasamento nos Parâmetros Curriculares Nacionais para o Ensino Médio (BRASIL, 2000), já que o documento defende a ideia de a escola se dispor em ressignificar o tempo, o espaço e os materiais escolares sempre que possível. As diferentes propostas pedagógicas devem refletir acerca do melhor equacionamento entre os variados recursos, sejam eles referentes a finanças, materiais, tempos e espaços escolares.

Ainda com vistas ao embasamento das nossas discussões, explicitamos as noções de letramento (BARTON E HAMILTON, 2000; KLEIMAN, 1995; OLIVEIRA, 2010a), gênero textual (BAZERMAN, 2011), eventos e práticas de letramento (BARTON E HAMILTON, 2000; HEATH, 1982), projetos de letramento (KLEIMAN, 2000; OLIVEIRA, 2008, 2010b), comunidade de aprendizagem (OLIVEIRA; TINOCO; SANTOS), e agente de letramento (KLEIMAN, 2007; SANTOS, 2012).

Metodologicamente, optamos pelo paradigma qualitativo de pesquisa (ANDRÉ, 1983), e pela abordagem etnográfica crítica (MOITA LOPES, 1993). A entrevista foi o instrumento de pesquisa mais pertinente para a geração dos dados. Os sujeitos entrevistados foram alunos das três séries do ensino médio que responderam a um questionário prévio, com perguntas que versavam sobre suas práticas de escrita, suas formas de produção, a regularidade de usos e os recursos referentes a essas práticas.

Como resultado, as reflexões desencadeadas pelo presente artigo mostram que ações ancoradas em PL são significativas porque estão alinhadas às reais dinâmicas da vida social. Buscamos contribuir para o entendimento de que as práticas de escrita dos alunos que ocorrem fora do espaço escolar podem ser uma importante fonte de inspiração para os direcionamentos e redirecionamentos das práticas didático-pedagógicas preocupadas com o ensino da escrita, principalmente aquelas que consideram fundamental o agir no mundo orientado por questões relacionadas ao meio social.

Não se trata, contudo, de uma idealização de PL, que sirva como modelo, já que a dinâmica desse dispositivo didático entende o aspecto contextual como decisivo para o planejamento e a execução das ações de ensino-aprendizagem a serem desenvolvidas. Este trabalho, portanto, é uma reflexão que remete a sugestões, posturas e encaminhamentos que levam em consideração os resultados apresentados pela pesquisa e os preceitos teóricometodológicos dos PL.

Necessariamente, não foi objetivo nosso afirmar que agir de determinada maneira e/ou realizar certa atividade pode garantir êxito em quaisquer processos de ensino-aprendizagem. Procuramos mostrar possibilidades que têm como norte as especificidades dos resultados da pesquisa e que podem fazer sentido apenas para as circunstâncias conjunturais desse contexto. De qualquer forma, esperamos que as reflexões possam dar margem a interpretações suscitadas por e para contextos outros e até ser suficientes para evidenciarem contrapontos ante outras formas de conceber o ensino-aprendizagem da escrita. 


\title{
1 Para entender os projetos de letramento
}

Para Kleiman (1995, p. 11), o letramento é o "conjunto de práticas sociais, cujos modos específicos de funcionamento têm implicações importantes para as formas pelas quais os sujeitos envolvidos nessas práticas constroem relações de identidade e de poder". Dessa forma, o letramento é entendido de maneira ampla, "como uma prática social plural e motivada por princípios de natureza ideológica” (OLIVEIRA, 2010a, p. 339).

O letramento é interdependente da realidade social, vai além de dicotomias e generalizações, leva em consideração todos os circuitos sociais existentes e não apenas os consagrados. O letramento é inseparável dos contextos sócio-histórico e ideológico nos quais a leitura e a escrita são utilizadas. Esses contextos abrangem, inclusive, a história de vida dos sujeitos, que são encarados como atores ativos e imprescindíveis, por isso, suas experiências de vida são um dos fatores que contribuem para a compreensão de uma dada interação. As pessoas usam o letramento para fazer mudanças em suas vidas, o letramento, por conseguinte, muda as pessoas.

Nessa perspectiva, Oliveira (2010a, p. 329, grifos da autora), ressalta que

\begin{abstract}
Enxergar o letramento como algo 'singular' é esquecer que a vida social é permeada por linguagem de múltiplas formas e destinada a diferentes usos. Nela, são veiculados gêneros diversos que são praticados por diferentes pessoas nas mais diversas atividades sociais, orientadas a partir de propósitos, funções, interesses e necessidades comunicativas específicas, não obstante a compreensão de que alguns textos são considerados canônicos e, por isso, mais legitimados que outros, socialmente [...]
\end{abstract}

Desse modo, a concepção de gênero por nós adotada é a que evoca ação social, conforme proposta por Bazerman (2011, p. 23), quando afirma que os “[...] gêneros não são apenas formas. Gêneros são formas de vida, modos de ser, são frames para a ação social". Bazerman (2011, p. 10) acrescenta ainda,

[...] gênero dá forma a nossas ações e intenções. É um meio de agência e não pode ser ensinado divorciado da ação e das situações dentro das quais aquelas ações são significativas e motivadoras. Assim como as ações, intenções e situações humanas, uma teoria de gênero precisa ser dinâmica e estar sempre mudando.

Outras considerações importantes acerca do letramento são as que englobam as noções de evento e prática de letramento. "Um evento de letramento é qualquer ocasião em que uma peça de escrita é parte integrante da natureza das interações dos participantes e seus processos interpretativos" (HEATH, 1982, p. 93). Qualquer prática cotidiana em que seja demandado o texto escrito é um evento de letramento, assim como postulam Barton e Hamilton (2000, p. 8) quando escrevem: "os eventos são episódios observáveis que surgem de práticas e são moldados por elas. A noção de eventos enfatiza a natureza situada do letramento, que sempre existe em um contexto social".

Já as práticas de letramento têm sentido mais amplo que os eventos de letramento, englobando-os. Barton e Hamilton (2000, p.8) descrevem as práticas de letramento como "as formas culturais gerais de utilizar a linguagem escrita que as pessoas aproveitam em suas vidas. No sentido mais simples, as práticas de letramento são o que as pessoas fazem com o letramento". As práticas de letramento envolvem valores, atitudes, sentimentos, elas advém das relações que ocorrem no meio social. Essas práticas mantêm estreita relação com as formas como as pessoas em uma cultura particular lidam com a escrita, como elas a utilizam e extraem sentido dela.

${ }^{3}$ Estão traduzidos para o português os trechos de edições em língua estrangeira citados neste texto. 
O conceito de PL, por sua vez, está imbricado às noções de gênero, eventos e práticas de letramento, já que, no trabalho com esse dispositivo didático, existe a preocupação com a vivência efetiva de gêneros em eventos respaldados por práticas de letramentos que ocorrem no meio social. Para Kleiman (2000, p. 238, grifos da autora), um PL é

\begin{abstract}
um conjunto de atividades que se origina de um interesse real na vida dos alunos e cuja realização envolve a escrita, isto é, a leitura de textos que, de fato, circulam na sociedade e a produção de textos que serão realmente lidos, em um trabalho coletivo de alunos e professor, cada um segundo sua capacidade. O projeto de letramento é uma prática social em que a escrita é utilizada para atingir algum outro fim, que vai além da mera aprendizagem da escrita.
\end{abstract}

Os PL são vistos como uma maneira de aprender diferenciada, que leva em conta formas de aprendizagem do dia a dia, em que o foco são as práticas sociais cotidianas. Dessa forma, Oliveira (2010c), afirma que não há a necessidade de se trabalhar com conteúdos programáticos predefinidos, pois o ponto de partida para o planejamento dos projetos deve ser a prática social, a demanda de situações específicas. Optar por trabalhar com os PL é atentar para as necessidades e interesses dos alunos, em especial para o contexto em que estão inseridos. Nesse sentido, é preciso haver sensibilidade à seleção dos conhecimentos e das práticas a serem abordados, primando pela significatividade.

Nessa perspectiva, os PL têm "como ponto de partida a prática social [...] visam atender a necessidades sociais e demandas comunicativas específicas de um determinado grupo, a partir de ações coletivas" (OLIVEIRA, 2010a, p. 340). Eles são "um modo de representação do mundo, mas como uma forma mediante a qual as pessoas exercem controle sobre a vida e atribuem sentidos não só ao que fazem, mas a si mesmas (OLIVEIRA, 2008, p. 104).

Nos PL, os modelos e programas de ensino prontos dão lugar à analise da totalidade dos fenômenos sociais, para que, frente a esse conhecimento, os indivíduos possam entendê-los e posicionar-se frente às questões que pautam o mundo, em vez de somente reproduzi-las. É, portanto, uma alternativa pedagógica que se baseia numa educação social, democrática e coletivista, que desacredita o individualismo e os relacionamentos sociais alienantes.

As ações ancoradas em PL se desenvolvem por meio de uma rede de ações coletivas e colaborativas, que visam ao desdobramento de necessidades que surgem de interesses da vida cotidiana de estudantes e professores. Essas ações, assim como outras práticas sociais, são mediadas pela leitura e pela escrita. Porém, diferentemente do que ocorre no ensino tradicional, elas têm uma função social real que não a de comprovar ao professor que já se sabe ler e escrever. Nesse dispositivo didático, a leitura e a escrita são instrumentos para que outras ações se realizem: ações sociais que ultrapassam os muros da escola.

Para Oliveira (2010b), os PL funcionam em comunidades de aprendizagem. Ela enfatiza que, nessas comunidades, a aprendizagem e o ensino se dão de maneira compartilhada, mediante engajamento, cooperação e empreendimento negociado. $\mathrm{Na}$ comunidade de aprendizagem, "alunos e professores, na qualidade de agentes de mudança, e num contínuo processo de construção do conhecimento, agem colaborativamente, potencializando recursos para compreender o mundo e alcançar resultados que verdadeiramente lhe interessam" (OLIVEIRA; TINOCO; SANTOS, 2014, p. 51).

Essa rede colaborativa é um dos pontos cruciais dos PL. Dessa forma, é interessante que o conceito de agente de letramento também seja compreendido. Pensar na apropriação da escrita em um contexto social determinado remete-nos à ideia de que existem indivíduos e/ou grupos deles atuando como mediadores nesse processo, ou seja, agentes humanos que interagem comunicativamente e propagam os usos da leitura e escrita. Esses indivíduos seriam, conforme Kleiman (2007, p.21) agentes de letramento, significando que 
O agente de letramento é capaz de articular interesses partilhados pelos aprendizes, organizar um grupo ou comunidade para a ação coletiva, auxiliar na tomada de decisões sobre determinados cursos de ação, interagir com outros agentes (outros professores, coordenadores, pais e mães da escola) de forma estratégica e modificar e transformar seus planos de ação segundo as necessidades em construção do grupo.

Cabe ressaltarmos, ainda, que, para ser um agente de letramento, não é necessário ou obrigatório estar atrelado a uma instância maior que promove sistematicamente a aprendizagem, como, por exemplo, a escola. Indivíduos podem ser agentes de letramento pelo simples fato de se relacionarem socialmente via ações que mobilizam gêneros. Eles seriam, conforme Santos (2012, p. 56), "pessoas engajadas no exercício do poder, no sentido de dominar habilidades [...] de linguagem com o propósito de produzir efeitos para (re)construir o mundo".

\section{Procedimentos metodológicos}

Neste estudo, a nossa opção metodológica foi por adotar o paradigma qualitativo de pesquisa (ANDRÉ, 1983), e a abordagem etnográfica crítica (MOITA LOPES, 1993). Optar por essa orientação condiz com a geração de dados mais detalhados que promovem interpretações mais ricas acerca da ação humana, dos comportamentos e das experiências dos colaboradores envolvidos na pesquisa.

A geração dos dados ocorreu, principalmente, mediante a realização de entrevistas direcionadas aos alunos. Procuramos empreender uma descrição ampla, que favoreceu a nossa compreensão acerca do objeto de pesquisa. A entrevista é uma oportunidade de conversa face a face, muito utilizada tanto para mapear, quanto para compreender o mundo da vida dos respondentes, pois ela fornece informações importantes para uma compreensão detalhada das crenças, das atitudes, dos valores e das motivações dos atores sociais e dos contextos sociais específicos.

As entrevistas foram realizadas com alunos das três séries do ensino médio de uma escola da rede pública estadual na cidade do Recife e ocorreram em diferentes momentos na periodicidade de um semestre letivo. Para a realização das entrevistas, elaboramos um questionário prévio com uma série de perguntas. Para cada uma das séries, selecionamos quatro alunos, dois do sexo masculino e dois do feminino, conforme a orientação da professora de língua portuguesa das turmas.

A entrevista possibilitou-nos, ainda, indagarmos os estudantes acerca de documentos, dados concretos, como fotografias e imagens que evidenciassem as respostas dadas. Essa foi, portanto, a segunda parte da nossa geração de dados, a busca por evidências materiais das práticas de escrita dos estudantes.

O desenho metodológico desta pesquisa visou colocar em prática o conjunto de procedimentos que darão conta de como serão gerados, analisados e discutidos os dados relacionados às práticas de escrita de alunos do ensino médio em contextos internos e externos à escola: pistas para a construção de projetos de letramento ${ }^{4}$.

\section{As práticas de escrita externas à escola}

Os desdobramentos apontados pelos dados gerados sinalizam para a ideia de que nos espaços sociais externos à escola os aspectos referentes ao tempo, espaço e materiais atrelados aos usos efetivos da escrita são múltiplos. Nossos resultados revelam as muitas possibilidades de

\footnotetext{
${ }^{4}$ Pesquisa orientada pela professora Dra. Maria Socorro Oliveira, do Programa de Pós-Graduação em Estudos da Linguagem da Universidade Federal do Rio Grande do Norte.
} 
tempo, de espaço e dos recursos que permeiam as ações dos sujeitos perante suas trajetórias cotidianas atravessadas pela escrita.

Para começamos, refletiremos sobre um dos questionamentos destinados aos alunos. Dele conseguimos deduzir algumas informações que podem nos ajudar a compreender alguns pontos da dinâmica temporal das práticas de escrita dos estudantes nos ambientes de interação externos à escola. Na pergunta, Com que frequência você pratica essa escrita?, a nossa meta foi compreender como se dá a periodicidade/regularidade das práticas de escrita desses sujeitos. $\mathrm{O}$ quadro abaixo apresenta o resumo das respostas:

\begin{tabular}{|c|c|}
\hline Práticas de escrita & Regularidade de manuseio \\
\hline Baterpapo (sincrono) & Todos os dias da semana \\
\hline Enviar mensagens & Todos os dias da semana \\
\hline Postar em microblog & Todos os dias da semana \\
\hline Produzir diário pessoal & Todos os dias da semana \\
\hline Escrever em barra de pesquisa & De 6 a 7 vezes por semana \\
\hline Legendar figuras/imagens/fotos & De 6 a 7 vezes por semana \\
\hline Fazer comentários & De 5 a 6 vezes por semana \\
\hline Postar em rede social & De 4 a 5 vezes por semana \\
\hline Elaborar conto & 4 vezes por semana \\
\hline Registrar lembretes/notas & 2 vezes por semana \\
\hline Registrar orações (religião) & De 1 a 2 vezes por semana \\
\hline Enviar e-mail & De 3 a 4 vezes por mês \\
\hline Elaborar lista de compras & 3 vezes por mês \\
\hline Enviar torpedo/mens. de texto & De 5 a 6 vezes ao ano \\
\hline Produ₹ir carta pessoal & 2 vezes por ano \\
\hline Preencher formulário (inscrição) & De 1 a 2 vezes por ano \\
\hline Preencher formulário (perfil) & 1 vez.por ano \\
\hline Elaborar currículo & 1 vez no ano \\
\hline
\end{tabular}

Quadro 1- Regularidade das ocorrências de práticas de escrita dos entrevistados Fonte: Dados da pesquisa.

Um dos dados mais emblemáticos mensurados a partir do quadro acima é a informação de que os entrevistados desenvolvem práticas de escrita em curtas periodicidades, revelando que eles demonstram interesse e gosto por desenvolvê-las. A importante reflexão que fazemos quanto a esse ponto é que a escrita é uma prática muito presente no dia a dia dos estudantes e essa presença se dá com relação ao exercício da produção textual já que o nosso questionamento se referia à ação de escrever.

A informação de que os alunos escrevem muito no seu dia a dia, além de ir à contramão do que muitos professores pensam, é pertinente porque revela um sujeito escrevente, que pratica a escrita cotidianamente sem a necessidade de comandos ou tarefas de cunho escolar, em diferentes momentos do dia, à medida que as necessidades surgem. A prática de escrita pode acontecer tanto em função de um chamamento ou uma notificação quanto pela curiosidade que ela provoca.

Uma das características dessas práticas cotidianas que nos interessam, nesse momento, diz respeito ao fato de os estudantes utilizarem a escrita para interagirem em vários momentos em um mesmo dia. Diferentemente do que ocorre na escola, os horários em que essa prática de escrita acontece são flexíveis, já que podem ocorrer a qualquer momento, em pequenos 
intervalos, como enquanto se caminha até a escola (ver figura abaixo). É uma dinâmica de prática de escrita que difere em muito das realizadas na escola, pois não há muita necessidade de seguir modelos prontos, rituais elaborados e, principalmente, é realizada onde e quando o sujeito achar pertinente.

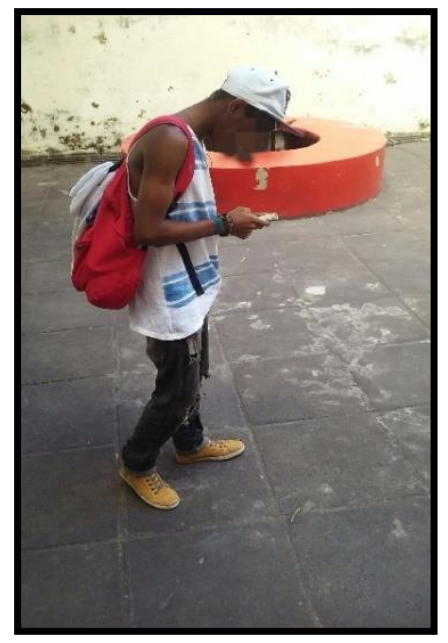

Figura 1 - Praticando a escrita no meio social externo à escola Fonte: Acervo da pesquisa.

Essa dinâmica das práticas de escrita cotidianas se revela significativa porque oportuniza aos alunos vivenciarem diferentes possibilidades temporais de desenvolver a escrita, eles sentemse à vontade quanto à escolha dos melhores momentos para apreciar informações e/ou as solicitações que recebem, porém, geralmente, eles encontram tempo para atendê-las.

É outro conceito de tempo, muito diferente do que acontece na escola, em que a regra é ensinar fragmentos de conhecimento distribuídos em pequenas parcelas de tempo, as aulas. $\mathrm{Na}$ vida externa à escola, os estudantes praticam a escrita de maneira completamente livre, sem determinações prontas, é uma prática que se ancora em hábitos e habilidades novas, carregada de características que lhes são próprias.

Todas as nossas reiterações em torno da compreensão do elemento tempo no cotidiano de práticas de escrita externas à escola ganham ainda mais destaque quando percebemos que o período gasto, diariamente, pelos estudantes em práticas de escrita cotidianas é muito relevante e extenso. Nos resultados apresentados no quadro abaixo, é possível percebermos que muitos desses momentos de uso efetivo da escrita podem ultrapassar, inclusive, o período de permanência desses estudantes na escola. A pergunta que gerou os dados apresentados no quadro foi Quanto tempo você leva para desenvolver essa prática de escrita?. Nesse momento, nosso objetivo maior foi depreender a real dimensão temporal dessas práticas no cotidiano dos estudantes.

\begin{tabular}{|l|c|}
\hline \multicolumn{1}{|c|}{ Práticas de escrita } & Tempo médio demandado $^{\mathbf{5}}$ \\
\hline Baterpapo (sincrono) & 74 minutos diários \\
\hline Produzir diário pessoal & 50 minutos diários \\
\hline Enviar mensagens & 26 minutos diários \\
\hline Postar em microblog & 25 minutos diários \\
\hline
\end{tabular}

\footnotetext{
${ }^{5}$ Nesse quesito, nosso intuito foi entender o tempo médio que os estudantes utilizam com a escrita em suas práticas externas à escola. Porém, os resultados mostrados nesse quadro compreendem a prática de modo geral, a escrita em si e também a leitura.
} 


\begin{tabular}{|l|c|}
\hline Elaborar conto & De 4 a 5 horas por semana \\
\hline Postar em rede social & De 3 a 4 horas por semana \\
\hline Escrever em barra de pesquisa & De 2 a 3 horas por semana \\
\hline Legendar figuras/imagens/fotos & De 2 a 3 horas por semana \\
\hline Fažer comentários & De 1 a 2 horas por semana \\
\hline Registrar orações (religião) & 1 hora por semana \\
\hline Registrar lembretes/notas & 10 minutos por semana \\
\hline Enviar e-mail & De 1 a 2 horas por mês \\
\hline Elaborar lista de compras & De 1 a 2 hora por mês \\
\hline Produziir carta pessoal & 9 horas por ano \\
\hline Enviar torpedo/mens. de texto & De 1 a 2 horas por ano \\
\hline Preencher formulário (inscrição) & De 1 a 2 horas por ano \\
\hline Preencher formulário (perfil) & 30 minutos por ano \\
\hline Elaborar curriculo & 30 minutos por ano \\
\hline
\end{tabular}

Quadro 2 - Tempo médio gasto diariamente pelos entrevistados em práticas de escrita Fonte: Acervo da pesquisa.

Os alunos demandam grande parte do tempo que têm em práticas de escrita cotidianas. Uma das características das práticas de escrita desenvolvidas pelos estudantes fora da escola é a sua estreita relação com as novas tecnologias da informação e comunicação, que são muito instigantes porque geralmente aliam a escrita a uma enorme variedade de outros recursos (interação instantânea, música, vídeos, jogos, imagens). Essa marca moderna das práticas de escrita acaba por tornar os estudantes, muitas vezes, usuários profícuos das tecnologias, haja vista a permanência de quatro ou mais horas diárias utilizando esses recursos.

Muitos dos estudantes mostraram respostas parecidas quanto às práticas de escrita que desenvolvem e o tempo que passam nessas práticas. E grande a atratividade que essas práticas de escrita externas à escola exercem em relação aos estudantes, muitos deles informaram que ficam curiosos para saber o que o aconteceu, para obter uma resposta, para instigar outros a falar etc. São essas as razões que os fazem passar muito tempo nessas práticas, eles as acham atrativas e, principalmente, porque, nesses momentos de interação, eles encontram os assuntos e sujeitos pelos quais mantêm afinidades. Os sujeitos, que demandam mais de uma hora diária batendo papo de maneira síncrona, fazem isso porque têm necessidades de fazê-lo. Além disso, essa é uma prática prazerosa, já que os estudantes em nenhum momento citaram ser obrigados a agirem dessa forma, eles passam esse tempo praticando essa escrita porque querem, gostam.

Cabe ressaltar que o fato de os alunos estarem passando longos períodos de tempo praticando uma escrita ligada à tecnologia não significa que esses usos sejam organizados e sistematizados. Essa enxurrada de dados acessados se apresenta de maneira segmentada, o acesso a informações por meio do uso das novas tecnologias geralmente ocorre ao passo do exagero e, assim, muitas vezes os alunos deixam de experimentar outras questões sociais e cria-se um congestionamento de informações adquiridas muitas vezes sem especificidade.

Ainda a respeito do nosso objeto de pesquisa, provocamos os entrevistados a responderem mais um questionamento. A pergunta dirigida aos alunos foi Em que local você desenvolven essa prática de escrita? Nossa busca visou entender quais e como são os locais onde a escrita é desenvolvida. Os resultados desse questionamento encontram-se apresentados no quadro abaixo: 


\begin{tabular}{|l|}
\hline Locais das práticas de escrita \\
\hline Própria residência \\
\hline Casa de amigos \\
\hline Rua \\
\hline Escola (pátio, corredores e refeitório) \\
\hline Instituicõoes (empresas, igreja) \\
\hline Lan house \\
\hline Quadro 3 - Locais onde as práticas de \\
escrita dos entrevistados ocorrem \\
Fonte: Acervo da pesquisa.
\end{tabular}

A grande maioria dos entrevistados afirmou que desenvolve práticas de escrita em casa, o que nos chamou atenção. Perguntados sobre o porquê de preferirem praticar a escrita em casa e não em outros locais, grande parte deles explicou que, por a internet ser um recurso indispensável para essa produção escrita, faz uso dessas práticas em casa, já que em outros locais não há oferta desse recurso.

Os estudantes sinalizaram, ainda, que, na escola, existe o serviço que disponibiliza rede de internet, via wi-fi, mas dificilmente o serviço funciona. $O$ aparato material que a escola dispõe não acompanha as evoluções vivenciadas pelos alunos em outras instâncias do meio social. O uso abusivo do livro didático e projetor multimídia convertem o ensino em algo descontextualizado, tornam a escola um ambiente limitado de possibilidades, em que a inovação e a transformação das atividades escolares ficam restritas, cabendo apenas a utilização de procedimentos de cunho conservador.

A escola pesquisada não atende às novas e reais necessidades de aprendizagem, os seus espaços e materiais mudaram muito pouco com o passar do tempo. Já os alunos parecem dominar a tecnologia, usam esses recursos materiais que são muito mais que meros suportes, apoios, eles fazem parte da vida dos sujeitos, são indispensáveis.

Os nossos dados mostram que os alunos estão cada vez mais habituados ao mundo digital. Eles estão desenvolvendo outras habilidades para escrever, usam os dedos tocando numa tela touch screen ou em teclados e fazem isso de maneira muito rápida e espontânea, às vezes, fazendo outras coisas enquanto digitam: andando, comendo, conversando com outras pessoas, assistindo à TV. Fica difícil dimensionarmos quais são os impactos de tantas mudanças, mas é interessante atentarmos para as "facilidades" que a digitação pode proporcionar: as autocorreções, as abreviações, o uso do não verbal, as práticas de control "c" - control "v". Voltarse contra essas práticas é ir de encontro ao que os estudantes fazem no dia a dia.

As práticas de letramento atuais propiciam posturas cada vez mais diversificadas por parte dos sujeitos. Eles aproveitam para interagir no pouco tempo entre uma tarefa e outra, às vezes alguns segundos são necessários para que consigam escrever algo, para interagir. Hoje, os sujeitos têm oportunidade de escrever no momento em que desejam, não é preciso apenas estar de posse de papel de caneta para poder fazer registros; de posse de um celular, eles fazem anotações rápidas, enviam ou gravam um áudio, comunicam-se por meio de viva voz.

Toda essa reflexão acerca da ressignificação do tempo, do espaço e dos materiais da escrita cotidiana externa à escola ganha ainda mais visibilidade quando percebemos que essas práticas são desenvolvidas mediante a utilização de recursos materiais que são acessíveis. Muitas vezes, essas práticas, que são extremamente eficientes do ponto de vista comunicativo, são realizadas por meio de suportes materiais simples como um celular ou um computador com acesso a internet. Na pergunta Quais recursos utilizou para desenvolver essa prática de escrita?, questionamos os estudantes sobre o apoio material necessário para suas práticas de escrita. Um resumo das respostas encontra-se disposto no quadro abaixo: 


\begin{tabular}{|l|}
\hline Recursos materiais necessários à escrita fora da escola \\
\hline Internet \\
\hline Celular próprio \\
\hline Computador da residência (Computador de mesa) \\
\hline Computador da residência (Computador portátil) \\
\hline Celular da mãe \\
\hline Papel e caneta ou lápis \\
\hline Lápis coloridos \\
\hline Fotografia \\
\hline Cola \\
\hline
\end{tabular}

Quadro 4 - Recursos materiais necessários às práticas de escrita dos entrevistados Fonte: Acervo da pesquisa

Grande parte dos recursos materiais necessários às práticas de escrita atuais é muito diferente dos clássicos papel e caneta/lápis utilizados na sala de aula. No meio social externo à escola, percebemos que outros recursos materiais estão sendo utilizados com muita frequência. Celulares, smartphones, computadores de mesa e portáteis ganham cada vez mais relevância.

Essa é a conjuntura atual em termos de recursos utilizados para apoiar a escrita. Com relação às ações que visam o desenvolvimento das práticas de escrita, é possível afirmar que os alunos as desenvolvem plenamente, independentemente de possuírem recursos materiais sofisticados. Uma maneira de explicarmos essa questão é refletindo sobre as informações do quadro acima. No dia a dia, os estudantes usam seus celulares para escrever, na falta deles, usam os celulares das mães, o computador da residência, eles fazem muita coisa com esses recursos. Os telefones celulares de hoje em dia - não necessariamente os mais caros - desempenham as mais variadas funções. Em termos de prática de escrita, por exemplo, eles podem ser usados para enviar mensagens eletrônicas, escrever em redes sociais, pesquisar, registar lembretes, interagir instantaneamente com outras pessoas, entre outros.

\section{$4 O$ que os resultados sugerem?}

Os desdobramentos apontados pelos dados gerados sinalizam para a ideia de que nos espaços sociais externos à escola os aspectos referentes ao tempo, ao espaço e aos materiais atrelados aos usos efetivos da escrita são múltiplos. Nossos resultados revelaram as muitas possibilidades de tempo, de espaço e dos recursos que permeiam as ações dos sujeitos perante suas trajetórias cotidianas atravessadas pela escrita.

Ao falarem sobre a regularidade com que praticam a escrita em ambientes externos à escola (vide quadro 1), os estudantes apontam para ocorrências que acontecem em curtas periodicidades. Os estudantes praticam a escrita espontânea externa à escola a todo momento. Eles mostram vontade, prazer ou necessidade de escrever, utilizam a escrita para interagir em vários momentos num mesmo dia, em horários flexíveis, a qualquer instante, em pequenos intervalos, e isso significa que as práticas de letramento às quais estão acostumados são assim, dinâmicas.

Professores e outros agentes de letramento precisam atentar para a série de características acerca de cada uma das práticas de escrita implicadas no meio social. Precisam compreender que

\footnotetext{
${ }^{6}$ Os resultados foram posicionados de acordo com o quantitativo de citações, do mais até o menos citado.
} 
os aspectos dessa escrita são primordiais aos PL nesses tempos de ampla interação porque podem aproximar as práticas de escrita da escola daquelas inerentes à convivência social.

Nos PL, essas novas características das práticas de escrita cotidianas podem revelar uma ressignificação das ações de ensino-aprendizagem porque esses dispositivos oportunizam aos alunos vivenciarem diferentes possibilidades temporais de desenvolver a escrita, em momentos diferentes daqueles proporcionados pela e na escola. É importante frisar, contudo, que é crucial estabelecer metas e também prazos. Cabe aos professores ou agentes de letramento conceber as situações de ensino-aprendizagem de modo que os estudantes sintam-se à vontade quanto à escolha dos melhores momentos para se executar as solicitações, porém elas sempre devem ser atendidas.

Os nossos achados sugerem, portanto, a adoção de ações de ensino-aprendizagem ancoradas nas novas práticas de letramento. Dessa forma, os PL precisam se preocupar em propiciar a exploração de textos em eventos de letramento perpassados pelo uso das novas tecnologias da informação e comunicação. Os professores e outros agentes de letramento, engajados a um dado PL, podem implementar perfis em rede social, sites, blogs etc., dedicados a promover e divulgar questões relacionadas aos assuntos os quais estão discutindo. Agindo assim, eles introduzem ao cotidiano escolar dos estudantes práticas de letramento alinhadas às demandas sociais externas à escola.

O desenvolvimento de uma atividade virtual pode ficar, portanto, sob a responsabilidade dos estudantes, com a respectiva coordenação de professores e outros agentes de letramento. Importante destacar, ainda, a necessidade de se assegurar a ampla participação de todos os estudantes, já que muitos alunos podem não possuir os meios necessários - conhecimento ou recursos - para o acesso à ferramenta virtual. Nesse sentido, diferentes grupos de alunos podem ser formados no sentido de ficarem responsáveis pela organização e divulgação de informações e dados, podendo se articular de diferentes maneiras, dentro e fora da escola, quanto às melhores formas e os tempos disponíveis para o desenvolvimento da atividade.

Os diferentes grupos formados podem ser divididos para ficarem responsáveis pelo desenvolvimento da atividade virtual a cada semana, por exemplo, de modo que fosse assegurada a ampla participação, numa periodicidade dinâmica. Numa atividade dessa natureza, os alunos podem ficar à vontade para desenvolverem suas atividades nos tempos que acharem pertinentes a depender das atribuições a que foram encarregados. A implementação da atividade pode ocorrer por meio do uso dos seus próprios celulares ou computadores e também via equipamentos e outros recursos disponibilizados pela escola.

O mais importante é que o uso da ferramenta virtual ocorra periodicamente, mas de maneira flexível, de forma que os diferentes grupos decidam os momentos ideais para fazê-lo. Os papeis de cada aluno no grupo podem ser monitorados pelos professores e outros agentes de letramento de maneira que as diferentes funções (editores, revisores, programadores, comentaristas) sejam estipuladas e alternadas regularmente e de acordo com as aptidões dos participantes.

As diferentes áreas do conhecimento podem estar a cargo da implementação de uma atividade dessas, uma vez que as contribuições podem partir de informações que conectam os mais variados assuntos. Acerca do desenvolvimento da prática efetiva da escrita, a riqueza de possibilidades ocorrerá independentemente de qual seja a disciplina responsável pelo desenvolvimento da atividade virtual. As vivências com diferentes gêneros textuais (notícias, depoimentos, reportagens, gráficos, legendas, programações, regulamentos, entrevistas, comentários etc), podem ser desenvolvidas sob a égide da significatividade e a serviço do desenvolvimento da competência comunicativa dos estudantes.

A ferramenta virtual selecionada, seja qual for a mais indicada, pode funcionar como o meio de comunicação para divulgar e ampliar às discussões que se estabelecem no PL. Nesse 
sentido, podem ser utilizados os diferentes gêneros textuais que se enquadrem aos objetivos e às necessidades de cada ação de ensino-aprendizagem.

A realização de uma atividade virtual pode potencializar as possibilidades comunicativas e de criatividade e, ao mesmo tempo, contribuir para que os alunos aprendam e interajam a partir do que é disponibilizado no ambiente. Além disso, a atividade, por despertar e instigar o interesse do aluno, faz com que ele busque autonomamente mais sobre o que é discutido, ampliando as possibilidades de construção do conhecimento.

Uma das grandes vantagens que uma ação nesses moldes pode acarretar diz respeito à ampliação do repertório referente a habilidades de organização do tempo. A obtenção do sucesso numa atividade dessas depende muito da organização temporal do grupo, os horários e dias específicos para o desenvolvimento da atividade virtual. Para isso, eles têm de organizar suas próprias agendas e tarefas e podem trocar experiências e informações em casa, na rua ou em qualquer outro ambiente que disponibilize os meios necessários para que isso se dê. Uma atividade dessa natureza perde completamente as características caso seja submetida ao espaço temporal dos 50 minutos, que é o tempo de duração de uma aula em turmas diurnas de ensino médio.

O tempo gasto pelos estudantes em práticas de escrita cotidianas externas a escola é muito relevante e extenso (vide quadro 2). Nesses momentos de uso efetivo da escrita, os alunos chegam a ultrapassar, diariamente, o período de permanência na escola. Dessa forma, não há razão em não recomendar aos alunos que desenvolvam tarefas de cunho extraescolar. É perfeitamente plausível que uma parte desse tempo demandado pelo aluno para a prática de escrita cotidiana seja também utilizado em prol de ações que contemplem a sua aprendizagem. É relevante frisar, mais uma vez, que a recomendação dessas atividades não deve ocorrer ao acaso, sem planejamento, muito menos apresentando contornos tradicionais.

O fato de alunos conviverem cotidianamente com muitas informações pode acarretar, ainda, na produção de um conhecimento descartável, que rapidamente é esquecido, já que o estudante geralmente não consegue sistematizar o que escreve ou lê. A ideia de as atividades dos PL se aliarem a essas práticas de escrita cotidianas dos alunos vem também no sentido de proporcionar mais qualidade a essas práticas, que o grande quantitativo de informações manuseadas pelos alunos atue também para sua formação, a construção do seu conhecimento.

A constante reorganização dos recursos materiais escolares é algo significativo porque é crucial atender às novas e reais necessidades sociais. A escola precisa repensar seus materiais de acordo com as atividades que precisam ser desenvolvidas e não o contrário. Eles são muito mais que meros suportes, apoios, fazem parte do âmago do processo de ensino-aprendizagem porque são imprescindíveis para o desenvolvimento de ações atreladas à realidade.

Se mudanças ocorrem no meio social, não há razão para que a escola pare no tempo. A reconfiguração dos recursos materiais pode acabar por mudar, também, os métodos utilizados para o ensino e isso é de grande relevância, pois se eles são significativos (inovadores, atrativos, atuais), estimulam a curiosidade e o interesse dos educandos, certamente facilitarão a aprendizagem. A inovação proporcionada pelo uso da internet, por exemplo, pode tornar as aulas mais participativas, interativas.

As novas tecnologias da informação e comunicação vêm revolucionando os processos de escrita. As ações ancoradas em PL devem estar a par desse aspecto, pois, no seu convívio com a escrita, os alunos já participam de ações em que a ela está associado o uso das novas tecnologias. Hoje, as diferentes categorias de suportes textuais que apoiam as práticas de escrita externas à escola pertencem em sua maioria a recursos de natureza digital: celulares, smartphones, computadores de mesa e portáteis (vide quadro 4), e a escola precisa atentar para esse fato.

Os PL devem incentivar as práticas efetivas de escrita e de leitura que coexistem no meio social e, por essa razão, é incoerente a escola não proporcionar ao aluno o convívio efetivo com a escrita ancorada em suportes digitais. Aqueles que atuam à luz da dinâmica dos PL devem se 
debruçar sobre a arquitetura do dispositivo didático e propiciar ações que levem em consideração os reais contextos situacionais vivenciados no meio social.

Desenvolver, nos contextos sociais escolares, ações que remetem a escrita digital é, acima tudo, evidenciar escolhas que os alunos fizeram espontaneamente em situações comunicativas realizadas em seu cotidiano fora da escola e consiste, também, no uso efetivo de materiais de ordem mais contemporânea. As práticas sociais atuais requerem o domínio de ferramentas ligadas à tecnologia e as formas de linguagem delas derivadas, como instrumentos para interação e inserção nas mais variadas situações sociais.

Já que as respostas dos estudantes suscitaram muitas questões que dizem respeito ao uso de novas tecnologias, os PL podem fomentar a utilização dos celulares que os próprios alunos manuseiam para o enriquecimento de atividades de ensino e aprendizagem. Os telefones celulares de hoje em dia desempenham múltiplas funções. Em termos de prática de escrita, por exemplo, eles podem ser usados para enviar mensagens eletrônicas, escrever em redes sociais, comentar, pesquisar, registar lembretes, interagir instantaneamente com outras pessoas, entre outros. As ações de ensino-aprendizagem ancoradas em PL, que sempre devem ser desenvolvidas sob o aspecto da ampla participação, podem fazer uso, por exemplo, dessa ferramenta aparentemente acessível aos alunos.

Professores e agentes de letramento precisam se reinventar, reutilizar, reciclar. É possível fazer muitas coisas com as possibilidades que estão à mão. Enquanto muitos professores desistem de implementar blogs, sites, grupos de mensagens instantâneas, apresentações multimídia, páginas na internet, por alegarem a não existência dos recursos materiais necessários, outros podem desenvolvê-las sem grandes sacrifícios, por meio de mobilizações que definam os melhores meios de vivenciá-las. Muitas vezes, os próprios alunos dispõem dos recursos ou conhecem alguém que pode cedê-los temporariamente.

É possível fazer muito a partir da realidade que se apresenta. É preciso preocupar-se em organizar suas ações levando também em consideração o arsenal de possibilidades que temos em mãos, pensando em como ele pode contribuir para a efetivação das atividades. Estamos refletindo sobre aspectos ligados à tecnologia, pois as informações contidas no quadro 4 sugerem a possibilidade do uso de recursos tecnológicos mesmo sem a escola disponibilizá-los. Porém, outras situações de ensino-aprendizagem podem ocorrer com base nessa premissa. Se a escola não dispõe de quase nenhum tipo de apoio material, por exemplo, a alternativa é conduzir os estudantes até ambientes em que os materiais a serem manuseados estariam disponíveis.

Nessa perspectiva, é de suma importância fazer com que a gerência de atividades realizadas fora dos muros da escola se torne um hábito. Visitas orientadas, uso de acervos e ambientes públicos, idas a instituições privadas, aulas de campo, estudos do meio, visitas externas, excursões e passeios, tudo isso pode fazer parte da rotina escolar mesmo não estando visível ou imposto pelas orientações curriculares. É necessário flexibilizar a permanência de estada em sala de aula, incrementando outros espaços e tempos de aprendizagem, principalmente no ensino médio, em que as ações desenvolvidas precisam ampliar as possibilidades de aprendizagem, integrando reflexão e ação, sem necessariamente, confinar essa integração exclusivamente no espaço da sala de aula.

Professores e outros agentes de letramento precisam pensar no currículo obrigatório integrado aos diversos ambientes próximos da realidade dos alunos e que podem ser explorados, para que possam vivenciar experiências práticas. Se os alunos estabelecem conexões entre o que aprendem e as situações reais, experimentais, ligadas ao que se estuda, a aprendizagem além de mais significativa, pode propiciar vivências que de fato representem ações sociais práticas, desenvolvidas sob a égide de necessidades sociais autênticas, em que as metas e os resultados visam ao atendimento de interesses ligados à escola e ao contexto.

Os PL são importantes instrumentos para a ressignificação dos espaços escolares porque atravessam a infraestrutura regular imposta pela escola. Não há razão para que todos os 
ambientes de ensino-aprendizagem proporcionados aos alunos se resumam ao espaço da escola. O desenvolvimento de habilidades e competências necessárias às vivências contemporâneas requer a utilização de espaços diversos e amplos, versáteis, alinhados a recursos materiais que estimulem a colaboração e a interação. As mudanças físicas e o conceito de ensinar e aprender nas escolas devem se transformar porque a arquitetura social desses novos tempos é outra. Os estudantes, por exemplo, vão a lan houses, desempenham atividades de escrita na rua, na casa dos colegas etc.

A escola precisa se apropriar do bairro, da comunidade e da cidade da qual faz parte. Professores, agentes de letramento e alunos devem sair mais juntos das escolas, as diferentes áreas do conhecimento e os conteúdos a serem debatidos nos PL podem guiar a criação de itinerários pedagógicos que mesclem circuitos culturais, ambientais e profissionais. Lembrando que essas ações não se tratam de passeios, são aulas-passeio, visitas guiadas, implementadas com $\mathrm{o}$ intuito de discutir, pensar e repensar os conhecimentos.

A premissa é que a escola seja o lugar da inovação e do acesso aos mais variados recursos e ambientes. É importante que a sala de aula abrace, ainda, os mais diversos gêneros e suportes textuais como, revistas, jornais, cordéis, quadrinhos, panfletos, títulos literários de todos os gêneros; que os ambientes específicos, tão importantes quanto os materiais, possam proporcionar o desenvolvimento de atividades diversas: bibliotecas, salas ou oficinas, os laboratórios, auditórios etc; enfim, que os PL sejam instrumentos para construção, movimentação e transformação dos espaços escolares, com vistas a satisfazerem as práticas de escrita baseadas nas demandas sociais.

\section{CONSIDERAÇÕES FINAIS}

As considerações desencadeadas por essa pesquisa apresentam reflexões acerca de como podemos pensar em ações de ensino-aprendizagem ancoradas em PL. O conjunto de reflexões empreendidas aqui contribui para o entendimento de que as práticas de escrita dos nossos alunos que ocorrem no espaço externo à escola podem ser uma importante fonte de inspiração para os direcionamentos e redirecionamentos das práticas didático-pedagógicas apoiadas por PL.

Os alunos desenvolvem práticas de escrita em curtas periodicidades de tempo, revelando que eles demonstram interesse e gosto por desenvolvê-las. O período gasto, diariamente, pelos estudantes em práticas de escrita cotidianas é muito relevante e extenso. Eles desenvolvem práticas de escrita em casa, na rua e usam recursos materiais diferentes dos clássicos papel e caneta/lápis; celulares, smartphones, computadores de mesa e portáteis ganham cada vez mais relevância.

Os desdobramentos apontados pelos dados gerados sinalizam para a ideia de que nos espaços sociais externos à escola os aspectos referentes ao tempo, espaço e materiais atrelados aos usos efetivos da escrita são múltiplos. Nossos resultados revelaram as muitas possibilidades de tempo, espaço e dos recursos que permeiam as ações dos sujeitos perante suas trajetórias cotidianas atravessadas pela escrita.

É necessário propiciar, nos contextos escolares, ações que remetem à escrita digital, à utilização de recursos materiais ancorados nas novas tecnologias. É importante que a escola busque por ambientes externos à escola para o desenvolvimento de atividades de ensinoaprendizagem, pois eles podem servir de mote para agregar às ações escolares maneiras de conceber a escrita baseadas nas demandas sociais atuais.

Dessa forma, é relevante que levemos em consideração as características reveladas pelo convívio dos estudantes com a escrita fora da escola. As revelações apontadas pelas práticas de escrita externas à escola podem inspirar práticas didático-pedagógicas preocupadas com o ensino da escrita orientado pelo agir no mundo. 


\section{REFERÊNCIAS BIBLIOGRÁFICAS}

ANDRÉ, M. E. D. A. Texto, contexto e significados: algumas questões na análise de dados qualitativos. Cadernos de Pesquisa, São Paulo, n. 45, p. 66-71, 1983.

BAZERMAN, C. Gênero, agência e escrita. $2^{a}$ ed. São Paulo: Cortez, 2011.

BARTON, D.; HAMILTON, M. Literacy practices. In: BARTON, D.; HAMILTON, M.; IVANIC, R. Situated literacies: reading and writing in context. London: Routledge, pp. 7-15, 2000.

BRASIL. Parâmetros Curriculares Nacionais - Ensino Médio: Linguagem, códigos e suas tecnologias. Brasília, DF: MEC/Secretaria de Educação Média e Tecnológica, 2000.

HEATH, S. B. Protean shapes in literacy events: Ever-shifting oral and literate traditions. In: TANNEN, D. (Ed.). Spoken and written language: Exploring orality and literacy. Norwood, N.J: Ablex, pp. $91-117,1982$.

KLEIMAN, A. B. Letramento e suas implicacoões para o ensino de Lingua materna. Signo. Santa Cruz do Sul, v. 32, n. 53, p. 1-25, dez, 2007.

O processo de aculturação pela escrita: ensino de forma ou aprendizagem da função? In: KLEIMAN, A. B.; SIGNORINI, I. (Org.). O ensino e a formação do professor: alfabetização de jovens e adultos. Porto Alegre: Artes Médicas do Sul, p. 223-243, 2000.

. Apresentação. In: KLEIMAN, A; SIGNORINI, I. (Org.). Os significados do letramento: uma nova perspectiva sobre a prática social da escrita. Campinas: Mercado das Letras, p.07- 11, 1995.

MOITA-LOPES, L. P. Etnografia crítica: um paradigma de pesquisa em Linguística Aplicada. Intercâmbio Puc SP, v 03, p. 1-16, 1993.

OLIVEIRA, M. do S. Projetos, uma prática de letramentos no cotidiano do professor de língua materna. In: OLIVEIRA, M. do S.; KLEIMAN, A. Letramentos múltiplos: agentes, prática, representações. Natal, RN: EDUFRN, p. 93-118, 2008.

Gêneros textuais e letramento. Revista Brasileira de Linguística Aplicada, Belo Horizonte, v. 10, n. 2, p. 325-345, 2010 a.

O Papel do Professor no Espaço da Cultura Letrada: do mediador ao agente de letramento. In: SERRANI, Silvana (Org.). Letramento, Discurso e Trabalbo Docente. Vinhedo: Editora Horizonte, p. 40-55, 2010b.

- Variação cultural e ensino/aprendizagem de língua materna: os projetos de letramento em comunidades de aprendizagem. In: VÓVIO, C.; SITO, L.; DE GRANDE, P. (Orgs.). Letramentos: rupturas, deslocamentos e repercussões de pesquisas em linguística aplicada. Campinas, SP: Mercado de Letras, p. 121-140, 2010c.

OLIVEIRA, M. S.; TINOCO, G. M. A. M.; SANTOS, I. B. A. Projetos de letramento e formação de professores de lingua materna. 2 ed. Natal: EDUFRN, 2014. 
SANTOS, I. B. A. Projetos de letramento na educação de jovens e adultos: o ensino da escrita em uma perspectiva emancipatória. Tese de doutorado. Programa de Pós-Graduação em Estudos da Linguagem. Universidade Federal do Rio Grande do Norte. Natal, 2012.

Recebido em 05/09/2017

Aceito em 09/10/2017

Publicado em 06/12/2017 